NBER WORKING PAPER SERIES

\title{
ASSESSING CONSUMER GAINS FROM A DRUG PRICE CONTROL POLICY IN THE U.S.
}

\author{
Rexford E. Santerre \\ John A Vernon \\ Working Paper 11139 \\ http://www.nber.org/papers/w11139
NATIONAL BUREAU OF ECONOMIC RESEARCH
1050 Massachusetts Avenue
Cambridge, MA 02138
February 2005

The authors thank Dennis Heffley, Carmelo Giaccotto, John M. Vernon, and Bob Hahn for their helpful comments on an earlier draft of this paper. The views expressed herein are those of the author(s) and do not necessarily reflect the views of the National Bureau of Economic Research.

(C) 2005 by Rexford E. Santerre and John A. Vernon. All rights reserved. Short sections of text, not to exceed two paragraphs, may be quoted without explicit permission provided that full credit, including () notice, is given to the source. 
Assessing Consumer Gains from a Drug Price Control Policy in the U.S.

Rexford E. Santerre and John A. Vernon

NBER Working Paper No. 11139

February 2005, Revised February 2006

JEL No. I1, L5, K2

\begin{abstract}
$\underline{\text { ABSTRACT }}$
This paper uses national data for the period 1960 to 2000 to estimate an aggregate private consumer demand for pharmaceuticals in the U.S. The estimated demand curve is then used to simulate the value of consumer surplus gains from a drug price control regime that holds drug price increases to the same rate of growth as the general consumer price level over the time period from 1981 to 2000. Based upon a 7 percent real interest rate, we find that the future value of consumer surplus gains from this hypothetical policy would have been $\$ 319$ billion at the end of 2000 . According to a recent study, that same drug price control regime would have led to 198 fewer new drugs being brought to the U.S. market over this period. Therefore, we approximate that the average social opportunity cost per drug developed during this period to be approximately $\$ 1.6$ billion. Recent research on the value of pharmaceuticals suggests that the social benefits of a new drug may be far greater than this estimated social opportunity cost.

Rexford Santerre

Department of Finance

University of Connecticut

2100 Hillside Road

Storrs, CT 06269-1041

rsanterre@business.uconn.edu

John Vernon

University of Connecticut

Department of Finance

2100 Hillside Road

Storrs, CT 06269-1041

and NBER

jvernon@business.uconn.edu
\end{abstract}




\section{Introduction}

The on-going public debate over prescription drug prices represents one of the most contentious issues in the history of U.S. healthcare politics. The commonly held perception that U.S. drug prices are "too high" has been fueled by the fact that real drug prices in the U.S. have been rising steadily, and at a rate faster than that of the general consumer price index for over two decades. As a result, the pharmaceutical industry has come under intense criticism, with both politicians and special interests groups calling for new legislation making pharmaceuticals more affordable, either through legalized reimportation from price-regulated markets such as Canada and the European Union, or more directly through government imposed price controls.

While these calls for legislative action are not new, the U.S. does appear to be, for the first time, very close to a major policy change regarding U.S. drug prices. ${ }^{1}$ The U.S. government may, like all other industrialized governments around the world, soon begin regulating drug prices ${ }^{2}$. In addition to several reimportation bills currently on the Senate floor, proposed amendments to the recently passed Medicare Modernization Act of 2003 also exist that will allow the U.S. government to negotiate directly with drug manufacturers for Medicare prescription drug purchases (the MMA currently has a noninterference clause), which will amount to approximately 60 percent of all U.S. drug purchases (Vernon, Santerre, and Giaccotto, 2004).

While regulated drug prices in the U.S. will undoubtedly improve the public's access to today's medicines, and thus generate both cost savings and improved public health, it will simultaneously reduce firms' incentives to invest in pharmaceutical R\&D because of lower levels of pharmaceutical profitability. Less investment in 
pharmaceutical $R \& D$ will have a negative effect on the rate of future pharmaceutical innovation. Recent research has documented the considerable benefits of pharmaceutical innovation in terms of improved longevity (Lichtenberg 2002; Miller and Frech, 2002) as well as the sensitivity of R\&D investment to real pharmaceutical prices (Giaccotto, Santerre, and Vernon, 2005) and profits (Vernon, 2004a). Thus, in addition to the shortrun benefits associated with lower, regulated drug prices, long-run costs also arise. This is precisely the tradeoff the U.S. patent system tries to balance by awarding limited-term patents to new drug products.

Even though a policy of regulated drug prices in the U.S. involves a tradeoff between short-run benefits and long run costs, the former outcome often receives more attention in policy debates (Scherer, 2004). Interestingly, however, efforts to quantify these short-run benefits from a rigorous economic perspective are nonexistent. Therefore, in the current paper, we attempt to do just that. We also compare our findings with the results from an earlier study by Giaccotto, Santerre, and Vernon (2005)—one that employed the same data and modeling techniques, but which measured the economic costs of the same U.S. price control policy—in terms of reduced levels of pharmaceutical innovation. Thus, we are able to weigh the benefits of pharmaceutical price controls (in terms of consumer surplus gains) against the costs (measured in terms of forgone drug discoveries). While these studies are retrospective in nature (out of necessity), and consider only one type of U.S. price control policy (one that requires pharmaceutical prices grow no faster than the consume price index), the price control policy simulated is, nevertheless, similar to an actual policy enacted in 1992 for drugs purchased by the government for the Veterans Administration (VA) health system. Moreover, and for the 
first time, a formal cost-benefit analysis of a particular type of drug price control is possible, and this may offer new insights.

Our paper proceeds as follows. In Section II we construct an empirical model of the aggregate consumer demand for pharmaceuticals in the United States. We also outline our empirical strategy and describe the data. Section III reports and discusses our empirical estimates. In Section IV we simulate the consumer surplus gains from a hypothetical price control policy in the U.S.: one that limits the growth rate of pharmaceutical prices to that of the consumer price index from 1981 to 2000 . We then assess the net benefit of this policy by comparing the gains of consumer surplus to some fairly plausible estimates of the value of the R\&D (and drugs) that would be lost had the policy been enacted. Section V provides a summary and offers some conclusions.

\section{Conceptual and Empirical Models of the Aggregate Consumer Demand for Pharmaceutical Products}

We begin by assuming a one-period model in which a representative consumer, given her exogenous tastes and preferences, $t$, derives utility from consuming the units of "health services", $s$, that flow from her health capital, $h$, and some composite good, $x$. Stated mathematically:

$U=U(s, x ; t)$

We also make the following standard assumptions about the individual's utility function:

$\frac{\partial U}{\partial s}>0 ; \quad \frac{\partial U}{\partial x}>0 ; \quad \frac{\partial^{2} U}{\partial s^{2}}<0 ; \quad \frac{\partial^{2} U}{\partial x^{2}}<0 ; \quad \frac{\partial^{2} U}{\partial s \partial x}>0$.

That is, utility is assumed to increase at a decreasing rate with respect to both health services and the composite good. We further assume that health services are produced 
with various combinations of prescription drugs, $q$ (e.g., dosages), and medical services, $m$ (such as office visits or inpatient days), conditioned on the representative consumer's initial endowment of health capital, $\mathrm{h}_{0}$. Thus, for ease of exposition, we ignore a set of other healthcare "goods" and "bads" such as exercise, diet, alcohol and tobacco use, etc. and the consumer's time involved in producing these healthcare activities. ${ }^{3}$ A production function for units of health services can thus be written as follows:

$s=s\left(q, m ; h_{0}\right)$,

where $\mathrm{s}$ is assumed to be concave with respect to both $q$ and $m$.

Substituting equation (2) into equation (1), allows utility to be expressed in terms of the production function for health services and the composite good. It is assumed that expenditures on the two inputs that produce health services, and spending on the composite good, fully exhaust the consumer's income net of insurance premiums, $y$. The consumer's optimization problem is therefore to select the amounts of prescription drugs, medical services, and the composite good that maximize her utility subject to the constraints of net income and the out-of-pocket prices for drugs, $P_{O}$, medical services, $P_{M}$, and the composite good, $P_{X}$. Stated more formally we have: ${ }^{4}$

Maximize $U=U\left[s\left(q, m ; h_{0}\right), x ; t\right] \quad$ s.t. $q P_{O}+m P_{M}+x P_{X}=y$.

Using the method of Lagrange Multipliers to find the solution to this constrained optimization problem generates the familiar first-order conditions. Using the first-order conditions, we can solve for the marginal rate of substitution between drugs and the composite good. This yields the following:

$\left[\frac{\partial U}{\partial s} \cdot \frac{\partial s}{\partial q}\right]\left[\frac{\partial U}{\partial x}\right]^{-1}=\frac{P_{O}}{P_{X}}$. 
The first partial derivative in the left-most bracket captures the marginal utility of good health while the second reflects the marginal productivity of drugs on good health. Equation (3) implies that, in equilibrium, the representative consumer equates the marginal benefit of the last drug consumed with its marginal cost, as reflected by the relative out-of-pocket price of an additional drug.

For purposes later in the paper, it is important to consider here that the marginal benefit of an additional drug dosage is influenced by both the value that the consumer places on being in a state of good health and the marginal product of an additional drug on good health. As a result, the price paid for an additional drug in the marketplace captures the consumer's willingness to pay for a small reduction in the probability of dying and/or a marginal improvement in her quality of life. This notion becomes particularly important when we use the demand curve to estimate the consumer surplus from a drug price control regime. That is, consumer surplus captures the value of life and the marginal contribution of an additional drug to good health.

Defining $x$ as the numeraire, it also follows from the utility maximization process that the representative consumer's quantity demanded of prescription drugs can be derived as a function of the relative out-of-pocket drug price, relative out-of-pocket medical price, and her real net income. Expressed generally, the demand function takes the following form:

$q=q\left(\frac{P_{O}}{P_{X}}, \frac{P_{M}}{P_{X}}, \frac{Y}{P_{X}} ; t, h_{0}\right)$.

Horizontally aggregating across all consumers, and assuming that the aggregate consumers' demand for prescription drugs can be written in log-log form for estimation purposes, the following result can be obtained: 
$\ln (Q)=\beta_{0}+\beta_{1} \ln \left(\frac{P_{O}}{P_{X}}\right)+\beta_{2} \ln \left(\frac{P_{M}}{P_{X}}\right)+\beta_{3} \ln \left(\frac{Y}{P_{X}}\right)$.

Given the log-log form, the coefficients in equation (5) may be interpreted as elasticities. According to the law of demand, the quantity demanded of prescription drugs should be inversely related to its relative out-of pocket market price $\left(\beta_{1}<0\right)$. The relationship between the quantity demanded of prescription drugs and the relative out-of-pocket price for medical services depends on whether pharmaceuticals and medical services are substitutes $\left(\beta_{2}>0\right)$ or complements $\left(\beta_{2}<0\right)$. Finally, if prescription drugs can be classified a normal good, real income will have a direct impact on the quantity demanded of prescription drugs $\left(\beta_{3}>0\right)$. Obviously, an inverse relation holds if prescription drugs are inferior goods.

Because we are interested in calculating the area under this demand curve for pharmaceutical products to measure the consumer surplus from a drug price control policy, the parameters of equation (5) are now estimated with multiple regression analysis. The empirical analysis is conducted at the macro level by using expenditure data from the health accounts at the Center for Medicare and Medicaid Services (CMS), price data from the Bureau of Labor Statisics (BLS), and income data from the Bureau of Economic Analysis (BEA) over the period from 1960 to 2000.

In the regression equation, real drug expenditures per capita serves as our measure of the quantity of drugs consumed, Q, the dependent variable in equation (5). Real pharmaceutical expenses per capita are calculated by dividing nominal drug expenditures by the pharmaceutical consumer price index and by population. Data for nominal pharmaceutical expenditures are obtained from the CMS. It should be noted that 
pharmaceutical expenditures capture purchases of both existing and new drugs but a demand curve assumes a standardized product. Technical change over time obviously changes the mix of old and new drugs and thus might present a problem when estimating long-run elasticities. However, variables are first differenced in our multiple regression models. Thus, we are estimating short-run elasticities and technical change therefore presents less of a problem.

The (nominal) out-of-pocket price of drugs is calculated in the following manner: $P_{0}=c P$,

such that the out-of-pocket price is determined by multiplying the average consumer coinsurance rate, $c$, by the price of pharmaceuticals, $P$. The expression in equation (6) is then divided by the price of the composite good, $\mathrm{P}_{\mathrm{X}}$, to derive the real out-of-pocket price of drugs. For empirical purposes, the average consumer coinsurance rate is measured by dividing all consumer out-of-pockets payments by total pharmaceutical expenditures. But theoretically, c should include just coinsurance payments because only coinsurance possesses a substitution effect. Unfortunately, separate data for various types of consumer payments are unavailable at CMS. Therefore, deductibles, copayments, and coinsurance payments must all be lumped together and treated similarly. Because of this data limitation, in the empirical analysis we allow c to interact with the price term as specified in equation (6), but also allow for our measure of $c$ to have its own separate impact on the consumption of drugs in a slightly alternative specification of equation (5).

The consumer price index (CPI) and its components, as calculated by BLS, provide our aggregate measures of pharmaceutical price, $\mathrm{P}$, medical price, $\mathrm{P}_{\mathrm{M}}$, and price of the composite good, $\mathrm{P}_{\mathrm{X}}$. As noted by several researchers, consumer price indices are 
not measured without error because substitution effects and quality changes over time are not fully incorporated (e.g., Hausman, 2003). Several authors have also pointed out the biases that previously existed in pharmaceutical price indices because of (1); the undersampling of new drugs, (2); the failure to treat generic drugs as lower-priced substitutes for branded drugs rather than new drugs, and (3); the use of list instead of transaction prices (Berndt, Griliches, and Rosett, 1993; Scherer, 1993).

Nevertheless, the pharmaceutical price index represents the best available time series indicator of drug price swings in the U.S. (Beginning in 1995, BLS has taken steps to correct some of these biases in the pharmaceutical price index (Santerre and Neun, 2000.)) Moreover, since we are examining changes in the ratio of the pharmaceutical and general CPI measures over time, some of the substitution and quality bias in the numerator and denominator may tend to cancel out. In addition, average year-to-year parameter estimates are obtained in the multiple regression analysis. These short-run estimates may avoid some of this bias because sufficient time does not pass for substitution effects and quality changes to fully work themselves out. It should be kept in mind, however, that any remaining measurement error biases the parameter estimates towards zero if the rest of the model is properly specified.

The real out-of-pocket price of medical care is obtained by multiplying the ratio of the medical care consumer price index and the general price index by the percent of medical care expenditures that were out-of-pocket expenses. Real net income per capita, $\mathrm{Y}$, is measured by real GDP per capita less real aggregate health insurance premiums per capita. Real GDP per capita data are obtained at BEA. Aggregate premium data are 
collected from the national health accounts at CMS, divided by population and the consumer price index to arrive at real aggregate health insurance premiums per capita.

Before presenting the multiple regression results, it might be instructive to discuss how real pharmaceutical expenditures per capita and the pharmaceutical out-of-pocket price and its components changed over time during the sample period. This information is provided in Exhibit 1. Notice that real drug expenditures per capita increased rapidly from 1960 to 1975 , continued to increase but at a diminishing rate from 1976 to 1994 , and then began increasing at an increasing rate once again from 1995 to 2000. These changes over time may reflect the law of demand given that out-of-pocket real prescription drug prices inversely mirrored these movements in per capita real drug expenditures during this time period. For instance, the out-of-pocket real price of drugs declined rapidly from 1960 to 1975 and from 1993 to 2000, the two time periods when real drug expenditures per capita were rising quickly. Attention should also be drawn to the fact that most of the changes in real drug expenditures have been driven more by adjustments in real drug prices than the consumer out-of-pocket share given that the consumer out-of-pocket share continued to decline throughout the period.

\section{Empirical Results}

A high degree of serial correlation necessitated first differencing of the data (after taking logarithms). First differencing of the data seems particularly appropriate because diagnostic tests revealed the presence of unit roots in several of the time series data (i.e., real drug spending per capita and real GDP per capita) before they were first differenced. Unit roots can result in spurious correlations among variables. We also included in our 
empirical model a lagged measure of real drug expenditures per capita as an additional independent variable (after first differencing). The lagged measure was included to control for unobserved demand factors like tastes and preferences, $T$, and the initial endowment of health, $H_{0}$, as specified in equation (4).

Both ordinary (OLS) and two stage least squares (TSLS) estimates of the parameters are obtained by the empirical analysis. The real long-term corporate AAA bond rate for all private industries and a one-year lagged pharmaceutical price index serve as instruments in the two stage least squares procedure. Specification of the real interest rate as a supply-side instrument is based on the notion that pharmaceutical companies tend to hold a sizeable stock of physical, R\&D/intellectual, and promotional capital. Over the long-run, pharmaceutical companies most likely attempt to earn sufficient revenues to cover the opportunity cost of holding these capital items through a series of short-run adjustments in drug prices. It stands to reason, therefore, that changes in real interest rates alter the opportunity cost of holding capital in the long-run and lead to corresponding adjustments in short-run prices. ${ }^{5}$ Note that this real interest rate is determined in the aggregate market for corporate loanable funds and outside the exclusive control of the pharmaceutical industry. It therefore can be treated as being exogenously determined.

As previously mentioned, two different OLS and TSLS specifications are estimated and reported. The restricted specification treats the out-of-pocket price, $\mathrm{cP}$, as an interactive term such that the coinsurance rate and pharmaceutical price share a similar elasticity. The unrestricted specification allows each component of the out-of-pocket price to separately enter the estimation equations so their elasticities can differ. Recall 
that our measure of $\mathrm{c}$, the coinsurance rate, may include copayments and deductibles, which theoretically possess income but not substitution effects. In addition, there is no theoretical reason to suspect that consumer response to changes in the coinsurance rate will be the same as that resulting from similar percentage changes in pharmaceutical prices.

The four regression results are reported in Exhibit $2 .{ }^{6,7}$ We note that, for a firstdifference model, a sizeable amount of the variation in the dependent variable is explained by the right hand side variables. As anticipated, all estimates of own-price elasticity of demand are negative and statistically significant. As one might expect, the TSLS procedure produces lower price-elasticity estimates than the OLS technique. In addition, it appears that consumers do not respond dramatically different to changes in the coinsurance rate than to similar percentage changes in drug prices given that the estimated coefficients on $\mathrm{c}$ and $\mathrm{P}$ are not statistically different from one another. Our short-run own-price elasticity estimates, ranging from -0.333 to -0.489 , are very close to Coulson and Stuart's (1995) longer-run estimate of -0.34 and also fall within previous estimates ranging from -0.06 to -0.64 as noted by these same authors. Earlier research focused on the demand for pharmaceuticals by elderly individuals. Our own-price elasticity is most likely slightly higher because it captures the demand of the representative consumer, rather than the representative elderly individual. Because of their relatively more depreciated health capital, elderly individuals are likely to face fewer health-related choices than the general population, and thus may possess less priceelastic demands for pharmaceuticals. However, it should be noted that our long-run price elasticity estimates are higher than those reported by Coulson and Stuart and range from 
-0.68 to $-0.92 .{ }^{8}$ These estimates still lie within the inelastic range as reported by prior research and probably reflect the relatively long adjustment period of 40 years.

The positive and statistically significant cross-price elasticity estimates suggest that medical care and prescription drugs are substitute products. For example, our results indicate that a 10 percent increase in the price of medical care is associated with a 4.5 to 5.6 percent increase in the quantity of prescription drugs demanded. The direct relation between the price of medical care and the quantity of prescription drugs demanded suggests that decision-makers have some ability to substitute one good for the other in the production of good health when relative prices change. This finding is consistent with Lichtenberg's (1996) research, which found that increased expenditures on pharmaceuticals lead to reduced expenditures on hospitalizations, ambulatory care, and physician services.

Net income elasticity estimates are positive and statistically significant, indicating that pharmaceutical products can, collectively, be treated as normal goods. The income elasticities are fairly sizable and suggest that a 10 percent increase in real income per capita produces a 5 percentage increase in the quantity of drugs demanded. Studies tend to suggest that health care represents a normal good (Santerre and Neun, 2004).

Although predominately influenced by private demand because public health insurance for pharmaceuticals was largely absent on an outpatient basis during the sample period, public financing may also influence total real drug expenditures per capita, the dependent variable in equation (5). During the time period under investigation, the government paid for drugs administered to inpatients if they were covered by one of the various public health insurance programs. The government also paid for prescription 
drugs for outpatient care under the Veterans Administration and Medicaid programs.

Reimbursement for pharmaceuticals is fairly restrictive under the latter two programs, but the programs do provide some of the population with financial access to pharmaceuticals. In any case, we considered it might be important to include in the multiple regression equation a control variable for the percentage of pharmaceutical expenditures paid by government. The government's share of spending on pharmaceuticals ranged from a little under 3 percent in 1960 to slightly under 22 percent in 2000. However, inclusion of this additional independent variable (after taking first differences in logarithms) did not significantly alter the results shown in Exhibit 2. In addition, the coefficient estimate on the public financing variable proved to be highly statistically insignificant. Public financing may have had no independent impact on pharmaceutical consumption because of its relatively low percentage over time, at least until very recently, or because this public financing variable captures a host of widely diverse government reimbursement schemes.

\section{Simulating Consumer Gains from a Drug Price Control Regime}

We now use the multiple regression results in Exhibit 2 to estimate the future value of the consumer surplus gains from a drug price control policy that holds drug price increases to the same rate of growth as the general price level over the period from the beginning of 1981 through the end of 2000. To measure the consumer surplus gains for each year, we estimate the area under the demand curve between the market and controlled prices. 
We pick the years between 1981 and 2000 to conduct the experiment because real drug prices increased throughout that period, as depicted in Exhibit 1. Moreover, in a recent study, Giaccotto, Santerre, and Vernon (2005) used that same period to estimate the number of new drugs that would have been lost from a similar drug price control regime. These authors assumed Congress enacted a law in 1980 requiring pharmaceutical prices in the U.S. to grow no faster than the general price level. This approach mirrors one of the actual mandates in the Veteran's Health Care Act of 1992: namely, that drug prices paid by federal agencies cannot grow at a rate faster than the urban consumer price index. Thus, while our experiment is couched within a hypothetical and historical context, it will nevertheless reflect an actual approach employed by the Federal government to control pharmaceutical prices (albeit on a relatively small scale). By combining the results from these two studies, some insight may be gained into the net consumer benefits arising from a drug price control system that holds the rate of growth of drug prices to the same rate of growth as the overall CPI.

Retrieving the elasticities from the multiple regression results shown in column 3 in Exhibit 2, we can express an aggregate consumer constant elasticity of demand curve for drugs in the following form:

$$
Q=A\left(\frac{P_{O}}{P_{X}}\right)^{-0.370}\left(\frac{P_{M}}{P_{X}}\right)^{0.459}\left(\frac{Y}{P_{X}}\right)^{0.519} Q_{t-1}^{0.517}
$$

Or more simply, we can write:

$$
Q=K\left(\frac{P_{O}}{P_{X}}\right)^{-0.370}
$$

and define, 
$K=A\left(\frac{P_{M}}{P_{X}}\right)^{0.459}\left(\frac{Y}{P_{X}}\right)^{0.519} Q_{t-1}^{0.517}$

It follows that $K$, the amount of drug consumption that results from all factors other than the real out-of-pocket price, can be determined by dividing $Q$, real pharmaceutical expenditures per capita, by $\left(\frac{P_{O}}{P_{x}}\right)^{-0.370}$ for each year between 1981 and 2000 . Using standard integration techniques, we estimate the area under the demand curve between the actual drug price index and the drug price index that would have resulted from a policy that held the rate of growth in pharmaceutical prices to that of the general consumer price index. For the purposes of our simulation, the price control policy holds the ratio of the market price of pharmaceutical goods to all other goods at the same level observed in 1980 .

Economic theory suggests that welfare gains should be measured off of the consumers' marginal benefit curve (notional demand) and not the effective demand curve which depends on the generosity of health insurance. Coinsurance provisions rotate the effective demand curve. Hence, it is imperative that $c$, the coinsurance rate, is held constant to estimate the marginal benefit curve and not some combination of the marginal benefit curve and effective demand curve. ${ }^{9}$ As a result, we perform simulations that hold $\mathrm{c}$ at a three different values throughout the period. More specifically, we set c equal to 1 such that the consumer is uninsured and set c equal to 0.67 and 0.45 , the optimal values for the coinsurance rate that were estimated by Feldstein (1973) and Manning and Marquis (1996), respectively. For sensitivity purposes we also experiment with several values for the own-price elasticity of demand and different values for the real return on savings (3, 7 and 10 percent) to compute the value of future consumer surplus gains. 
Own-price elasticity is assumed to be -0.370 , as described above, and values that are onehalf and twice that amount.

The results of the consumer surplus simulations are shown in Exhibit 3. Not surprisingly, the future value of consumer surplus gains increases with own-price elasticity of demand (because the price control generates greater quantity demanded), the coinsurance rate (because consumers personally have more to gain), and the real interest rate on savings. Exhibit 3 shows that the estimates of the future value of consumer surplus gains range from $\$ 176$ to $\$ 767$ billion for various values of the three key variables. This represents the range of savings that would have accrued to consumers at the end of the 20 year period if government had held the rate of growth of drug prices to the same rate of growth as the overall consumer price index. It also reflects the future value of annual improvements in health because of better financial access to existing drugs as a result of the price control. Thus, at first blush, it appears that a drug price control of this type could have benefited consumers by a considerable amount in terms of the greater longevity and quality of lives that lower pharmaceutical prices could have purchased in the short-run.

However, over this same time period, Giaccotto, Santerre, and Vernon (2005) estimated that this same price control regime would have caused firms to reduce pharmaceutical R\&D expenditures (in $\$ 2000$ ) by between $\$ 264.5$ and $\$ 293.1$ billion, because of lower profit expectations and possibly reduced levels of internal funds (which are the primary source of $R \& D$ finance $)^{10}$. This reduced investment in $R \& D$ would have led to approximately 38 percent fewer new drugs being brought to market in the global economy. If this 38 percent figure is applied to the total number of new chemical entities 
approved for marketing during this period in the U.S., we can use our simulation results to calculate the average social opportunity cost per new drug.

During the period from 1980 to 2000, 520 new chemical entities were approved for marketing in the U.S. ${ }^{11}$ This figure suggests that 198 drugs would have been "lost" if the assumed price control regime was imposed. Dividing the $\$ 176$ to $\$ 767$ billion of consumer surplus gains from price controls over the period from 1980-2000 by the number of new drugs "lost" due to price controls, we estimate that, on average, consumers (in the aggregate) gave up $\$ 0.9$ to $\$ 3.9$ billion in consumer surplus per new drug developed. Moreover, assuming the most likely values for the real interest rate (3 percent), the coinsurance rate (45 percent) and the price elasticity of demand (-0.37), consumers would have lost about $\$ 1.1$ billion of surplus per new drug developed.

This raises the question of whether or not the benefit of a new drug brought to market during this period was greater than or less than this range of estimates. If the former is the case, then the fact that price controls were not imposed (in the manner we describe and model) was, on net, good for the U.S. If, however, the latter is the case, then not imposing price controls had a net social cost for Americans. While recent research has documented the significant benefits associated with medical and pharmaceutical research, and even suggested that U.S. may be currently underinvesting in R\&D (Murphy and Topel, 2003), very few studies have documented the value (in dollar terms) of new drugs or pharmaceutical R\&D. A notable exception is the econometric study by Lichtenberg (2002). In his study, which covered a similar time period in the U.S. (1960-1997), Lichtenberg approximated that, on average, every $\$ 1,345$ spent on pharmaceutical R\&D “produced” an additional U.S. life year. 
While speculative, we can use this average productivity measure of $R \& D$ to compare the benefits of price controls (as modeled in this study) and the costs in terms of "lost" R\&D and drugs ${ }^{12}$. To do this we divide Giaccotto and colleague's estimated range of forgone capitalized pharmaceutical R\&D (\$264.5 to \$293.1 billion), by $\$ 1,345$ and multiply this by $\$ 100,000$, which is one measure of the value of a U.S. life year (Cutler and McClellan, 2001). Of course, both higher and lower estimates of the value of a life year exist. This simple first approximation places the cost of our hypothetical price control policy at between $\$ 19.7$ and $\$ 21.8$ trillion in terms of value of lives lost. This range of figures is over 28 times larger than our estimated range for the consumer surplus gains produced by this drug price control policy ( $\$ 176$ to $\$ 767$ billion). This leads to the conclusion that a price control regime of the type described here would have done much more harm than good from a social welfare perspective.

One very important caveat should be mentioned at this point. Our analysis implicitly assumes a market environment in which drug firms either unilaterally or collectively are capable of exercising market power by restricting output and raising prices. Based upon several structural characteristics (e.g., few dominant firms, brand names, patents, and huge role of promotion expenditures) and the relatively high profitability of this industry, it may seem reasonable to assume that pharmaceutical companies truly possess some degree of market power. If drug firms do exercise market power then theory suggests that a price control can lead to increased output supplied and greater consumer surplus and our estimates of the welfare loss remain intact.

However, if drug firms in the aggregate behave competitively rather than exercise market power, our estimates of the consumer surplus gains from a drug price control 
regime will be overestimated because firms will react to the price control by reducing output below the competitive level. Indeed, one might argue that countervailing forces such as generic competition and managed care buyers induce a sufficient amount of competition into an otherwise structurally oligopolistic industry. It follows that drug price controls will impose an even greater net burden on society than that estimated in this paper if the aggregate pharmaceutical industry behaves reasonably competitive. Thus our estimates of the potential damages from a drug price control policy, at least the type entertained here, may be conservative.

\section{Conclusion}

Rising drug prices have captured the attention of the media, various public interest groups, and politicians. Some have pointed to price controls as a way of reining in what many perceive as "runaway" drug prices. But as economists have known for centuries, price controls simply represent "bad economics". Economic theory suggests that price controls often create shortages, reduce quality, lead to price discrimination, and can harm incentives for innovation. The only benefit to price controls is that some individuals gain, at the expense of others, through an increase in their consumer surplus as a result of the lower controlled prices.

In this paper, we estimate the consumer surplus gains, or benefit, resulting from a hypothetical price control policy in the U.S. To accomplish this objective, we use national data from 1960 to 2000 to estimate the aggregate demand for pharmaceuticals. Based upon our empirical results, the demand for pharmaceuticals is shown to be inversely related to its own-price and directly related to the both medical prices and real 
income. Moreover, the empirical estimation generates elasticity estimates with plausible magnitudes that are in general agreement with previous research findings.

We then use the parameters from the estimated demand curve to simulate the consumer surplus gains associated with an assumed price control policy that holds the increase in pharmaceutical prices to the rate of growth of the general consumer price index. Giaccotto, Santerre, and Vernon (2005) have conducted this same experiment, and found that this same price control regime would have reduced the number of new drug innovations by about 38 percent. For the nation as a whole and using the most likely values, we estimate that the future value of the consumer surplus from the assumed price control regime would equal about $\$ 221$ billion in 2000 . On a per drug basis, we estimate that the consumer opportunity cost of not imposing this price control policy was approximately $\$ 1.1$ billion. However, when compared to the estimated benefits of the additional pharmaceutical $R \& D$ that was undertaken because these hypothetical price controls were not implemented, these costs appear to be very small. Given our results, and those reported in prior research, society may be better off discovering more efficient ways than price controls to improve access to existing drugs. 


\section{References}

Berndt, Ernst R., Zvi Griliches, and Joshua G. Rosett. 1993. Auditing the producer price index: micro evidence from prescription pharmaceutical preparations. Journal of Business and Economic Statistics 11(3): 251-64.

Coulson, N. Edward and Bruce C. Stuart. 1995. Insurance choice and the demand for prescription drugs. Southern Economic Journal, 61: 1146-57.

Congressional Budget Office (http://www.cbo.gov/ ): Cost Estimate for H.R. 1 Medicare Prescription Drug, Improvement and Modernization Act of 2003 (and personal conversation with W. Philip Ellis from the CBO on December 3, 2003)

Cutler, David and Mark McClellan. 2001. Is technological change in medicine worth it? Health Affairs. Sept/Oct; pp. 11-29.

Feldstein, Martin S. 1973. The welfare loss of excess of health insurance. Journal of Political Economy 81(2): 251-80.

Giaccotto, Carmelo, Rexford E. Santerre, and John A. Vernon. 2005. Drug prices and R\&D investment behavior in the pharmaceutical industry. Journal of Law and Economics 48(1): 195-214. 
Hausman, Jerry. 2003. Sources of bias and solutions to bias in the consumer price index. Journal of Economic Perspectives 17(1): 23-44.

Kanavos P., J. Costa-i-Font, S. Merkur, and M. Gemmill. 2004. The economic impact of pharmaceutical parallel trade in European Union member states: a stakeholders analysis. London School of Economics and Political Science working paper

Lichtenberg, Frank. 1996. Do (more and better) drugs keep people out of hospitals? American Economic Review 86, May, 384-8.

Lichtenberg, Frank. 2000. The effect of pharmaceutical utilisation and innovation on hospitalisation and mortality. In Productivity, Technology, and Economic Growth, ed. by B. van Ark, S. K. Kuipers and G. Kuper (Kluwer Academic Publishers)

Lichtenberg, Frank. 2002. Sources of U.S. longevity increase, 1960-1997. National Bureau of Economic Research, working paper 8755, Cambridge, MA.

Maddala, G.S. 1992. Introduction to Econometrics, New York: Macmillian Publishing Company.

Manning, W.G. and M.S. Marquis. 1996. Health insurance: The tradeoff between risk pooling and moral hazard. Journal of Health Economics 15(5): 609-639. 
Miller, Richard D. Jr. and H.E. Frech III. 2002. The productivity of health care and pharmaceuticals: quality of life, cause of death, and the role of obesity. Mimeo, University of California at Santa Barbara.

Murphy Kevin and Topel Robert. 2003. The economic value of medical research. In Measuring the gains from medical research; edited by Kevin M. Murphy and Robert H. Topel, The University of Chicago Press.

Santerre, Rexford E. and Stephen P. Neun. 2004. Health economics: theories, insights, and industry studies, Thomson Learning.

Scherer, F.M. 2001. The link between gross profitability and pharmaceutical R\&D spending. Health Affairs 20: 216-220.

Scherer, F.M. 2004. The pharmaceutical industry-prices and progress. The New England Journal of Medicine 351:927-932.

Schwartzman, David. 1976. Innovation in the pharmaceutical industry: the declining profitability of drug innovation, Baltimore: John Hopkins Press.

Vernon, John A. 2004. New evidence on drug price controls. Regulation 27(3): 13-15. 
Vernon, John A., Santerre, Rexford E., and Giaccotto, Carmello. 2004. Are drug price controls good for your health? University of Connecticut, Department of Finance, Working Paper.

Vernon, John A. 2005. Examining the link between price regulation and pharmaceutical R\&D investment. Health Economics (14):1, 1-17. 


\section{Exhibit 2:}

\section{OLS and TSLS Regression Results}

(Standard Errors Shown in Parentheses)

\begin{tabular}{|c|c|c|c|c|}
\hline Explanatory Variable & $\begin{array}{l}\text { OLS } \\
\text { Restricted } \\
\text { Results } \\
\end{array}$ & $\begin{array}{l}\text { OLS } \\
\text { Unrestricted } \\
\text { Results }\end{array}$ & $\begin{array}{l}\text { TSLS } \\
\text { Restricted } \\
\text { Results } \\
\end{array}$ & $\begin{array}{l}\text { TSLS } \\
\text { Unrestricted } \\
\text { Results }\end{array}$ \\
\hline Log of out-of-pocket real price & $-0.476^{\text {** }}$ & & $-0.370^{* *}$ & \\
\hline of drugs $\left[\mathrm{c}\left(\mathrm{P}_{\mathrm{Q}} / \mathrm{P}_{\mathrm{X}}\right)\right]$ & $(0.131)$ & & $(0.139)$ & \\
\hline Log of out-of-pocket fraction (c) & & $\begin{array}{l}-0.489^{* *} \\
(0.166)\end{array}$ & & $\begin{array}{l}-0.419^{* * *} \\
(0.171)\end{array}$ \\
\hline Log of real price of drugs $\left(\mathrm{P}_{\mathrm{Q}} / \mathrm{P}_{\mathrm{X}}\right)$ & & $\begin{array}{l}-0.468^{* *} \\
(0.147)\end{array}$ & & $\begin{array}{l}-0.333^{*} \\
(0.159)\end{array}$ \\
\hline $\begin{array}{l}\text { Log of out-of-pocket real price of } \\
\text { medical care }\left(\mathrm{P}_{\mathrm{M}} / \mathrm{P}_{\mathrm{X}}\right)\end{array}$ & $\begin{array}{l}0.557^{* *} \\
(0.186)\end{array}$ & $\begin{array}{l}0.555^{* *} \\
(0.189)\end{array}$ & $\begin{array}{l}0.459^{*} \\
(0.192)\end{array}$ & $\begin{array}{l}0.449^{*} \\
(0.196)\end{array}$ \\
\hline $\begin{array}{l}\text { Log of real GDP per capita less } \\
\text { premiums per capita } \\
\left(\mathrm{Y}_{\mathrm{N}} / \mathrm{P}_{\mathrm{X}}\right)\end{array}$ & $\begin{array}{l}0.502^{* *} \\
(0.174)\end{array}$ & $\begin{array}{l}0.496^{* * \%} \\
(0.183)\end{array}$ & $\begin{array}{l}0.519^{* *} \\
(0.175)\end{array}$ & $\begin{array}{l}0.494^{*} \\
(0.185)\end{array}$ \\
\hline $\begin{array}{l}\text { Log of one-year lagged measure of } \\
\text { real pharmaceutical expenditures }\end{array}$ & $\begin{array}{l}0.469^{* *} \\
(0.112)\end{array}$ & $\begin{array}{l}-0.468^{* *} \\
(0.114)\end{array}$ & $\begin{array}{l}0.517^{* *} \\
(0.115)\end{array}$ & $\begin{array}{l}0.513^{* *} \\
(0.117)\end{array}$ \\
\hline per capita & & & & \\
\hline
\end{tabular}

\begin{tabular}{|c|c|c|c|c|}
\hline Adjusted $\mathrm{R}^{2}$ & 0.578 & 0.566 & 0.571 & 0.556 \\
\hline Durbin Watson Statistic & 1.83 & 1.84 & 1.99 & 2.00 \\
\hline Observations & 39 & 39 & 39 & 39 \\
\hline
\end{tabular}

* Denotes significance at the $5 \%$ level

** Denotes statistically significant at the $1 \%$ level or better 


\section{Exhibit 5}

Future Value of the Consumer Surplus for Various Rates of Return, Own-Price Elasticities, and Co-insurance Rates (Values are in Billions of 2000 US\$)

\begin{tabular}{|c|c|c|c|}
\hline $\begin{array}{l}\text { Own-price Elasticity }\left(\mathrm{E}_{\mathrm{qp}}\right) \text { and Co- } \\
\text { insurance Rate }(\mathrm{C})\end{array}$ & $\begin{array}{l}3 \% \text { Interest } \\
\text { Rate }\end{array}$ & $\begin{array}{l}7 \% \text { Interest } \\
\text { Rate }\end{array}$ & $\begin{array}{l}11 \% \text { Interest } \\
\text { Rate }\end{array}$ \\
\hline \multicolumn{4}{|l|}{$E_{q p}=-0.370$} \\
\hline $\mathrm{C}=0.45$ & $\$ 221$ & $\$ 291$ & $\$ 391$ \\
\hline $\mathrm{C}=0.67$ & $\$ 284$ & $\$ 374$ & $\$ 502$ \\
\hline $\mathrm{C}=1.00$ & $\$ 366$ & $\$ 481$ & $\$ 646$ \\
\hline \multicolumn{4}{|l|}{$E_{q p}=-0.185$} \\
\hline$C=0.45$ & $\$ 176$ & $\$ 232$ & $\$ 310$ \\
\hline$C=0.67$ & $\$ 244$ & $\$ 320$ & $\$ 429$ \\
\hline $\mathrm{C}=1.00$ & $\$ 338$ & $\$ 443$ & $\$ 594$ \\
\hline \multicolumn{4}{|l|}{$E_{q p}=-0.740$} \\
\hline$C=0.45$ & $\$ 350$ & $\$ 462$ & $\$ 623$ \\
\hline $\mathrm{C}=0.67$ & $\$ 388$ & $\$ 512$ & $\$ 691$ \\
\hline $\mathrm{C}=1.00$ & $\$ 431$ & $\$ 569$ & $\$ 767$ \\
\hline
\end{tabular}




\section{Exhibit 1:}

Real Drug Expenditures per capita, Out-of-Pocket Real Price of Drugs and Out-ofPocket Real Price of Medical Care Over Time in the U.S.

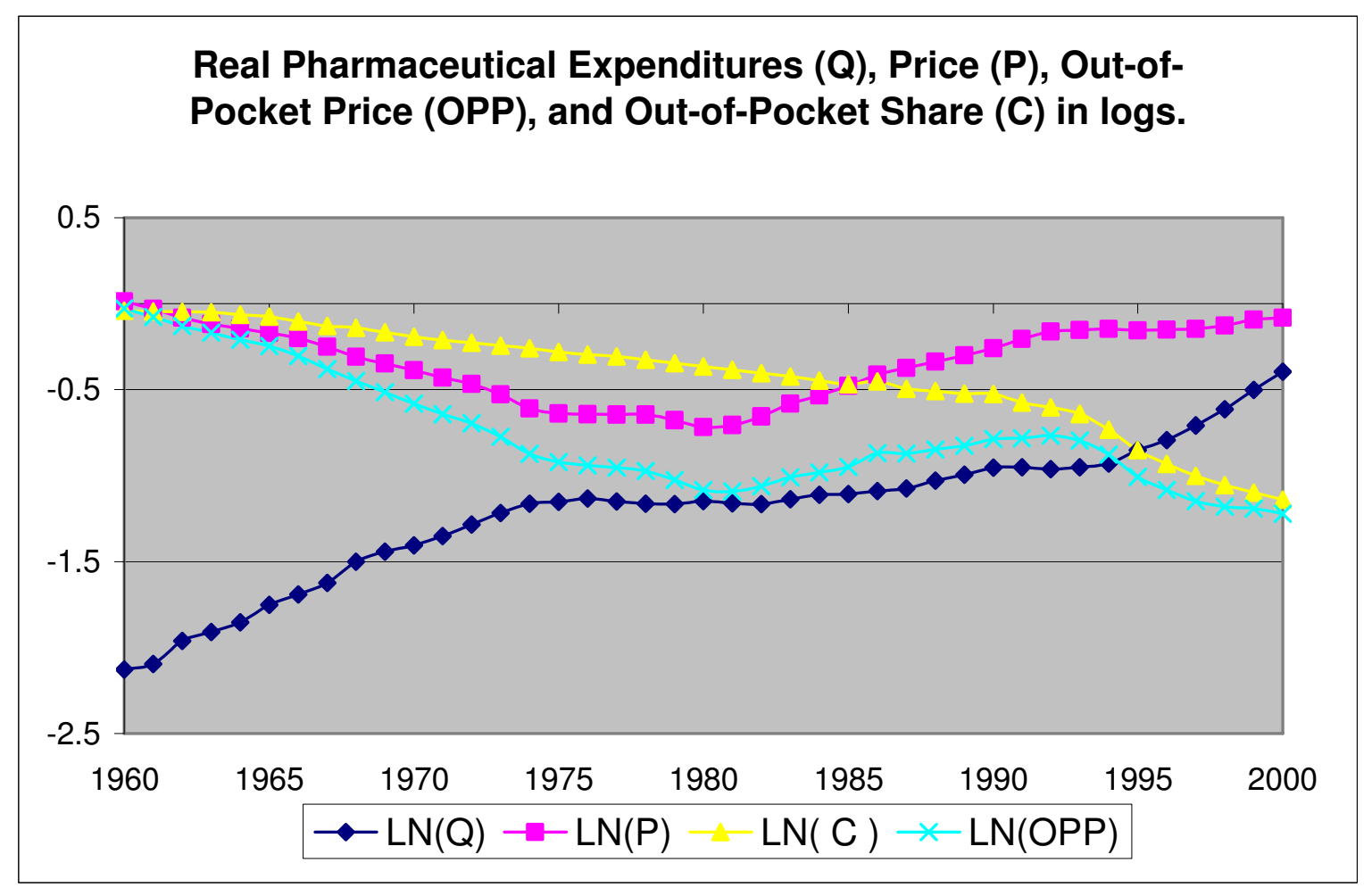




\section{Appendix 1:}

Variable Statistics and Data Sources

\begin{tabular}{|c|c|c|c|c|c|}
\hline Variable & Mean & Median & Max & Min & SD \\
\hline Real pharmaceutical price index & 0.726 & 0.734 & 1.013 & 0.489 & 0.155 \\
\hline Out-of-pocket real price of drugs & 0.495 & 0.420 & 0.973 & 0.295 & 0.187 \\
\hline \multicolumn{6}{|l|}{ Out-of-pocket fraction of private } \\
\hline pharmaceutical expenditures & 0.686 & 0.694 & 0.960 & 0.320 & 0.187 \\
\hline \multicolumn{6}{|c|}{ Out-of pocket real medical price index } \\
\hline & 0.315 & 0.271 & 0.552 & 0.167 & 0.122 \\
\hline \multicolumn{6}{|c|}{ Real GDP per capita less real premium per } \\
\hline capita & 21.50 & 21.10 & 32.08 & 12.99 & 5.24 \\
\hline \multicolumn{6}{|c|}{ Per capita real private drug expenditures } \\
\hline & 0.320 & 0.317 & 0.673 & 0.119 & 0.122 \\
\hline \multicolumn{6}{|c|}{ Real long-term corporate AAA bond rate all } \\
\hline private U.S. industries & 3.59 & 3.85 & 8.83 & -2.47 & 2.54 \\
\hline
\end{tabular}

${ }^{\wedge}$ All data except the corporate bond rate were obtained at the Bureau of Labor Statistics (http://www.bls.gov), Center for Medicare and Medicaid Services (http://www.cms.gov), and the Bureau of Economic Analysis (http://www.bea.gov). The corporate bond rate data were obtained at the Federal Reserve (http://federalreserve.gov). 


\section{Appendix 2:}

First-Stage Regression Results Used in TSLS Model (Standard Errors Shown in Parentheses)

\begin{tabular}{ll}
\hline Explanatory Variable & $\begin{array}{l}\text { Coefficient } \\
\text { Estimate }\end{array}$ \\
\hline Log of out-of-pocket real price of medical & $0.230^{* *}$ \\
care $\left(\mathrm{P}_{\mathrm{M}} / \mathrm{P}_{\mathrm{X}}\right)$ & $(0.081)$ \\
\hline Log of real GDP per capita & $-0.196^{*}$ \\
$\left(\mathrm{Y} / \mathrm{P}_{\mathrm{X}}\right)$ & $(0.095)$ \\
\hline Log of one-year lagged measure of real & 0.060 \\
pharmaceutical expenditures per capita & $(0.061)$ \\
\hline Log of out-of-pocket fraction of private & 0.045 \\
pharmaceutical expenditures (c) & $(0.079)$ \\
\hline Log of one-year lagged out-of-pocket real & $0.880^{* *}$ \\
pharmaceutical price index & $(0.064)$ \\
\hline Real long-term corporate AAA bond rate & $0.008^{* *}$ \\
\hline
\end{tabular}

\begin{tabular}{ll}
\hline Adjusted $\mathrm{R}^{2}$ & 0.919
\end{tabular}

\begin{tabular}{ll}
\hline Durbin Watson Statistic & 1.98
\end{tabular}

Observations

39

* Denotes significance at the 5\% level

** Denotes statistically significant at the $1 \%$ level or better 


\section{Endnotes (Footnotes)}

${ }^{1}$ Approximately 10 years ago the Clinton Administration's Health Security Act had provisions for directly controlling drug prices. In addition, the drug industry has been under the political microscope since the 1960s (Scherer, 2004)

${ }^{2}$ There are numerous theoretical reasons why reimportation may not generate the desired prescription drug cost savings that the advocates of this and related policies expect. See, for example, the paper by Kanavos et al. (2004). If this occurs, direct price regulation will have to follow to procure the cost savings that such reimportation policies were intended to achieve.

${ }^{3}$ For instance, Miller and Frech (2002) examine empirically the effect of pharmaceuticals, medical care, and various lifestyle factors on measures of the quality and quantity of life using a sample of OECD countries. Among other results, they find that pharmaceutical consumption extends and improves lives. ${ }^{4}$ For simplicity, it is assumed that the decision to purchase pharmaceutical and medical expense insurance coverage has already been made.

${ }^{5}$ First stage results can be found in Appendix 2. Note that a sizeable proportion of the variation in drug prices is explained by the right hand side variables and that both instruments possess plausible signs and are statistically significant.

${ }^{6}$ Mathematically, the intercept term in equation (7) falls out after first differencing of the variables. Statistically, an intercept term proved to be no different from zero.

${ }^{7}$ As noted in the text, a one-period lagged value of Q (in logs) was also included in the specification to control for changing tastes and preferences and initial endowment of health. Because a lagged value of the dependent variable is specified on the right hand side of the equation, the typical Durbin Watson statistic cannot be used to detect serial correlation. We remind the reader, however, that our specification contains first differences of the variables and not levels so we report the Durbin Watson statistic. We also experimented with other diagnostic tests such as the Q-statistic and Durbin's alternative test (Maddala, 1992). These tests failed to detect the presence of serial correlation.

${ }^{8}$ Long run price elasticity estimates can be derived by dividing the short run elasticity by one minus the coefficient estimate on the lagged dependent variable.

${ }^{9} \mathrm{We}$ thank the reviewers for emphasizing this point.

${ }^{10}$ The latter would be the case if capital market imperfections imparted a cost advantage to internal funds over external debt and equity (see Vernon, 2005).

${ }^{11}$ Federal Drug Administration at http://www.FDA.gov.

${ }^{12}$ See the papers by Vernon, Santerre, and Giaccotto (2004), and Vernon (2004) for a discussion of the caveats involved. 